\title{
Las mujeres en los materiales curriculares: el caso de dos libros de texto de educación física Women in curriculum materials: the case of two physical education textbooks \\ Nuria Sánchez Hernández, Daniel Martos-Garcia, Ana López Navajas \\ Universidad de Valencia(España)
}

Resumen. A pesar de los mandatos legales, los libros de texto siguen manteniendo un tratamiento discriminatorio en cuestiones de género. Así, la revisión de la literatura al respecto muestra evidencias de que deberían cuestionarse las características del currículum oculto. En este sentido, el trabajo que presentamos tiene como propósito analizar la presencia de las mujeres en los libros de texto de $3^{\circ}$ y $4^{\circ}$ de ESO usados en educación física de las editoriales Teide y Serbal con el objetivo de determinar en qué momentos y formas se da dicho sesgo de género. Para ello, se ha desarrollado un análisis cualitativo y cuantitativo tanto de las imágenes como del contenido de los textos y se ha realizado un análisis frecuencial de los mismos para medir la presencia y recurrencia de las mujeres. Los resultados muestran una escasa presencia de mujeres en los manuales, estando el sexismo más presente en el texto que en las imágenes. De hecho, en una editorial ni siquiera aparecen referencias al género femenino. Los datos relativos al tratamiento diferenciado por sexos son los que muestran más claramente la inadecuación de los contenidos, lo que contraviene además la legislación vigente. Por tanto, resulta necesaria la revisión de dichos libros por parte de las editoriales, para aumentar la presencia de las mujeres y ofrecer modelos femeninos. Mientras esto ocurre, se propone el uso de los libros en el aula de forma crítica y la puesta en marcha de nuevas investigaciones al respecto.

Palabras Clave. Educación Física, libros de texto, sexismo, Secundaria, currículum oculto.

Abstract. Despite legal regulations, textbooks still maintain a discriminative treatment towards women. Current evidence suggests that aspects on the hidden curriculum need to be addressed. The purpose of this study is to analyse the presence of women in two textbooks, edited respectively by Teide and Serbal publishing houses, and used in ninth and tenth grade of secondary education Physical Education. In particular, this work aims to discern whether there is a slant towards men or women throughout textbooks. Content and images from the two books were examined employing quantitative and a qualitative analysis. Women's frequency of presence and recurrence were measured. Results from the study reveal a discrimination pattern towards women, which is more evident within the text than in the images. In fact, in one of the textbooks, references to women are not present at all. Data related to gender-differentiated treatment in specific topics clearly shows an inappropriate use of contents, which breaks current educational regulations. Therefore, a revision of textbooks is needed from publishing houses, with the aim to increase the presence and display of female models throughout books. Meanwhile, a critical use of textbooks and further research in this field are suggested.

Keywords. Physical Education, textbook, sexism, secondary school, hidden curriculum.

No se puede usted imaginar el coñazo de cuentos que leíamos en clase, la locomotora solidaria, el cirujano responsable, el árbol que se hizo amigo de un caracol, el fusil que se negaba a disparar... Cada protagonista blanco tenía un amigo negro, o chicano, y el sexo de los protagonistas estaba rigurosamente equilibrado, el mismo número de niños que de niñas. Cuando aparecía una mujer mayor, era ingeniera, o directora de orquesta. Los hombres, en cambio, lavaban los platosy no sabían conducir. Para realidad virtual, aquello. Todo mentira.

(Atlas de Geografía humana, de Almudena Grandes)

\section{Introducción}

Son varias las esferas sociales en las que la presencia y participación de la mujer ha mejorado de forma considerable, una de ellas la educativa. Sin embargo, aún estamos muy lejos de una educación que procure la igualdad entre mujeres y hombres y esta, por el contrario, sigue siendo una fuente frecuente de desigualdades (López-Navajas, 2014). Esto nos parece relevante puesto que la escuela es un agente importante de socialización (Hamodi, 2014) y, con la adecuada orientación, podría contribuir a combatir las desigualdades y cuestionar las expectativas que la sociedad tiene sobre cada uno de los géneros (Gómez, Ortega, \& Sainz, 2008; Posada, 2008). En la escuela se aprenden normas y códigos que van a definirnos como seres sociales (Fernández, 2002), por ello, lo que aquí se aprenda determinará después, entre muchos otros, fenómenos como la desigualdad o la violencia de género. No es baladí, siguiendo datos del informe 'Mujeres y Hombres en España' (Instituto de la Mujer, 2014), la existencia de diversos indicadores que muestran como en nuestra sociedad la discriminación por motivos de sexo no acaba de desaparecer, ni la brecha de género en las tasas de empleo, en las tasas de paro, en la percepción salarial o en las horas dedicadas a tareas del hogar, por no hablar del número de mujeres asesinadas por violencia de género y que en el año 2014 fue de 54 mujeres y en 2015 ascendió a 56 (www.msssi.gob.es).

Fecha recepción: 31-03-16. Fecha de aceptación: 18-01-17 Daniel Martos Garcia daniel.martos@uv.es
En este sentido, la legislación educativa recoge sobre el papel una igualdad formal, como se refleja en la Ley Orgánica de Educación(LOE) cuando conmina a «Valorar y respetar la diferencia de sexos y la igualdad de derechos y oportunidades (...)» (2006, artículo 23). Por su parte, la Ley para la Mejora de la Calidad Educativa (LOMCE) mantiene que «En ningún caso habrá discriminación por razón de nacimiento, raza, sexo (...)» (2013, artículo 61), entre otras cosas. Sin embargo, las leyes no siempre caminan en la misma dirección; así, la LOMCE, después de consagrar la no discriminación por razón alguna, a renglón seguido da cobertura legal a la educación diferenciada por sexos (2013, artículo 61). Cabría aquí preguntarnos, ¿ ¿podría haber establecido una educación diferenciada por razas? ¿Por qué por sexos sí? Este hecho pone encima de la mesa, como apuntábamos antes, que existen todavía aspectos que mejorar de forma sustantiva. Por ejemplo, es manifiesta la falta de reconocimiento al protagonismo y la importancia de las mujeres en las diferentes áreas de conocimiento (Blanco, 2000; López-Navajas, 2014), lo que hace de la educación un proceso que continua albergando y promocionando actitudes sexistas a través, sobre todo, de un androcentrismo en el que no reparamos. En muchos casos, las mujeres no cuentan, son invisibilizadas y parecen irrelevantes en el desarrollo histórico, cultural y científico. Por otra parte, y en línea con los intereses de este estudio, se antoja pertinente la revisión y adecuación de los materiales curriculares y su papel en la reproducción de estereotipos de género (Michel, 1987).

En esta dirección, tampoco la asignatura de educación física (EF, a partir de ahora), se libra de la presencia de estereotipos de índole sexista (Scraton, 1992; Fernández, 2002; Pelegrín, León, Ortega, \& Garcés, 2012). Por ejemplo, está comprobado el uso habitual de deportes en los que predominan estereotipos masculinos frente a otro tipo de deportes asociados a rasgos femeninos (Duran, Lavega, Salas, Tamarit, \& Invernó, 2015), confirmando así la presencia de un modelo sexista en las clases prácticas. Bien es cierto que las injusticias son ahora menos evidentes que en épocas pasadas por lo que son menos reconocibles, aunque éstas sigan existiendo (Vilanova, \& Soler, 2012). Si esto es así, parece entonces lógico prestar atención al llamado currículum oculto y su papel en la perpetuación de los modelos tradicionales y que, en relación con el género, fomenta la desigualdad (Devís, Fuentes, \& Sparkes, 2005; Vilanova \& Soler, 2012). Además de las intenciones y expectativas 
manifiestas en programaciones de aula y otros documentos de esta índole, la educación se compone a su vez de gestos y actitudes, miradas y sobre todo de omisiones que de forma sutil pero inevitable conforman el proceso de enseñanza y aprendizaje.

Uno de los elementos más usados en educación, y que da pie a este trabajo, es el de los materiales curriculares, y más concretamente los libros de texto para el alumnado (Devís, Peiró, Molina, Villamón,Antolín, \& Roda, 2001). Su presencia y uso es indiscutible en todas las áreas de conocimiento y ello hace que sea necesario prestarle especial atención para evaluar lo que transmite al alumnado (Gonzalez-Palomares \& Rey-Cao, 2015). Aunque en EF su utilización es menor por diversas razones, los libros de texto siguen teniendo una responsabilidad esencial en la transmisión del conocimiento de nuestra asignatura(Molina, Peiró \& Devís, 2004). Sin embargo, mientras en otras disciplinas el libro de texto ha sido motivo de atención por parte de los y las investigadoras (Garreta \& Careaga, 1987; Subirats, 1993; Blanco, 2000; Peñalver, 2001, \& López-Navajas, 2014) en el área que nos ocupa se percibe cierta falta de atención académica (Táboas, \& Rey, 2011). Por eso, nos ha parecido adecuado el estudio de los libros de texto de EF.

A pesar de que su uso se ha extendido, el libro de texto no se ha librado de las críticas de aquellos que veían en él un limitador de la creatividad docente (Freire, 1990), o de quienes aluden a su papel de reproducción de un saber empaquetado y previamente fijado (Martínez Bonafé, 2002). Por consiguiente, parece relevante hacer notar que no se puede considerar los libros de texto como materiales neutrales a disposición del profesorado, sino que estos contribuyen a la transmisión de valores y modelos hegemónicos (Piedra, Ramírez-Macías, \& Latorre, 2014). Por ello, su uso obedece a una opción moral y política sobre la educación (Devís et al., 2001) y proporciona una visión hegemónica sobre esta. Los libros de texto no recogen la pluralidad del entorno y en cuestiones de género no atiende a sus variadas realidades, por lo que su elección se debe hacer después de analizar el tipo de material y su currículum oculto (Moya, Ros, Bastida, \& Menescardi, 2013). A pesar de su controversia y de que, referenciando a Táboas y Rey (2011), éstos transmiten una visión androcéntrica y hegemónica, no se trata de denigrar su uso sino más bien de hacerlo desde una perspectiva de experimentación (Devís et al., 2001). Consecuentemente, su aplicación, lejos de ser automática y acrítica, puede conllevar la participación activa de profesorado y convertirse en un instrumento para el desarrollo de una actitud crítica en el alumnado, por ejemplo, para el cuestionamiento del modelo hegemónico del cuerpo (Pedraz, 2010). Para ello, señalaremos sus carencias con el objetivo de corregirlas y propondremos algunos usos concretos.

En esta tesitura, en los últimos cuarenta años ha surgido un interés por este tema, sobre todo en ciertas áreas de conocimiento, localizadas en los años 70 y 90 (Devís et al., 2001), al albur de las renovaciones educativas habidas en el estado español. Los primeros trabajos que se realizaron en áreas como matemáticas o lengua (Chevalland \& Joshua, 1982; Moreno, 1986; Villella, 2004), ya ponían de manifiesto la necesidad de análisis de los materiales curriculares. En EF el interés es tardío y los estudios sobre libros de texto no comienzan a aparecer hasta bien entrados los años 80 (Delgado, Barrera, \& Medina, 1992; Devís, 1998; Devís et al., 2001; Fernández Truán, 1996; González, \& González, 1996; López Rodríguez, 2001; Molina et al., 2004; Muñoz, Olivera, Pérez, Sánchez, \& Sainz, 1988). Paralelamente al estudio de los libros de texto, surge la preocupación por el currículum oculto que transmiten y, concretamente, los estereotipos de género que difunden estos materiales curriculares.

En la etapa de Secundaria y Bachillerato el estudio llevado a cabo por Parra (2002) puede que sea el pionero en este sentido; en él se analiza las imágenes y el texto de 15 libros de la época de la LOGSE(Ley de Ordenación General del Sistema Educativo) y donde concluye, no solo que las mujeres están infrarrepresentadas, sino que se asocian mayoritariamente a las actividades expresivas y a deportes como la gimnasia rítmica. Por el contrario, los hombres se asocian al atletismo o al fútbol, lo que contraviene las intenciones de la ley acerca de la igualdad de género.
A partir de los trabajos de Parra (2002), se suceden las investigaciones y los resultados de las mismas, de una forma u otra, vienen a corroborar la existencia de estereotipos sexistas en los libros de texto. Así, Táboas y Rey $(2007,2011)$ analizan las imágenes de dos libros de texto usados en EF, y los resultados arrojan una mayor presencia del hombre en dichas imágenes y una asociación de la mujer con actividades no deportivas. Por su parte, González (2005) desarrolla un análisis de contenido de 17 libros de texto de ocho editoriales usados en EF en la etapa de la LOGSE (1990) y concluye que existe el sexismo en dichos materiales, entre otras cosas, por la abrumadora presencia de hombres en las imágenes publicadas.

En la etapa de Primaria, encontramos los trabajos de Moya, Ros y Menescardi (2014) y Moya et al. (2013), en el que desarrollan un análisis de contenido adaptando la herramienta diseñada por Táboas y Rey (2007) para la etapa elegida. En el segundo trabajo, que atiende a la variable del género, los datos del estudio de nueve libros de texto de cinco editoriales distintas concluyen que, aunque la presencia de hombres es mayor que la de mujeres, no se da un trato desigual en cuanto a la asociación de dichas imágenes con actividades físicas distintas. Finalmente, Martínez Bello (2013) se ha ocupado de la etapa de Infantil con el análisis de contenido de tres libros de texto en los que se ha constatado que la presencia de hombres no es mayor que el de las mujeres, al contrario de lo que ocurre en las otras etapas. Como contrastó hace más de 20 años Subirats (1993) y ratificó López-Navajas (2014), la presencia de mujeres disminuye a medida que subimos de nivel educativo.

En esta situación, el presente trabajo pretende ahondar en el estudio de la presencia y recurrencia de las mujeres en los libros de texto de la asignatura de EF, lo que proporciona información pertinente para establecer cómo actuar (López-Navajas, 2014), en este caso en la asignatura de EF. Así, nos planteamos como objetivo observar cuál es la presencia y recurrencia de las mujeres en los libros de texto deEF para determinar cómo se encuentran representadas, cuál es su peso en ellos y si existe un tratamiento diferenciado en dichos libros. Para ello:

- Determinaremos la presencia y la recurrencia de los personajes, es decir, el número de veces que cada uno de ellos aparece en el texto. Esto nos proporcionará una idea de la importancia que se le concede a cada uno de los sexos.

- Analizaremos en el bloque de Condición Física de ambos libros si hay un tratamiento diferenciado por sexos en los contenidos de cada uno de los temas. Existe un dimorfismo sexual del que los manuales deben dar cuenta y es en este bloque donde más se puede notar. Se ha escogido únicamente este bloque porque en él el tratamiento de la diferenciabiológica es relevante.

- Mediremos la prevalencia deportiva de las mujeres en los deportes que aparecen practicando, tanto a través de imágenes como de las referencias.

- Analizaremos las imágenes de los libros para observar el porcentaje de mujeres que aparecen en los manuales.

- Compararemos los resultados de cada editorial, para comprobar si existen diferencias remarcables en el tratamiento del tema.

Además, como consecuencia de nuestros resultados, plantearemos algunas medidas a tomar por parte de las editoriales y las personas responsables de las políticas públicas y el profesorado en cuestión.

\section{Metodología}

En este estudio se ha desarrollado un análisis de contenido, siguiendo los pasos descritos en otros trabajos similares (López-Navajas, 2014; Moya et al., 2013; Táboas \& Rey, 2007, 2011). Las categorías de análisis que hemos empleado son las siguientes:

- Por un lado, hemos analizado la presencia (p) y recurrencia (r) de mujeres y hombres en los contenidos de los libros de texto, con el propósito de valorar la importancia de las deportistas en ellos. Para este análisis hemos seguido el método empleado por López-Navajas (2014). Para determinar la presencia (p), se han contado las mujeres y los hombres con nombre propio que aparecen. Estos personajes aportan información en calidad de referencias deportivas y modelos. Para la 
recurrencia (r), que es el parámetro de referencia, se ha hecho un conteo de todas las veces que han aparecido deportistas mujeres y hombres en los textos. Esta variable muestra la relevancia tanto de los personajes como de los sexos. Por último se han establecido los porcentajes de presencia femenina de ambos indicadores.

- Para profundizar en el análisis cualitativo se ha querido comprobar si existe un tratamiento diferenciado de los sexos en aquellos temas donde este es pertinente. Así se ha analizado en los libros si en el bloque de Condición Física existe este tratamiento, lo que indicaría un nivel de calidad didáctica adecuado. Para el análisis de las imágenes se han seleccionado aquellas que tienen presencia humana, desechando el resto de imágenes y se han desagregado en tres categorías: las que son de mujeres, de hombres o de ambos. El establecimiento de las imágenes masculinas y femeninas se ha realizado de la siguiente manera: se ha considerado masculinas $\left(\mathbf{H}_{\mathbf{i}}\right)$ las imágenes de hombres más la mitad de las que tienen representación de ambos sexos. Para las mujeres $\left(\mathbf{M}_{\mathbf{i}}\right)$ se ha seguido el mismo procedimiento: se han sumado las imágenes de mujeres a la mitad de las imágenes donde aparecen ambos. Se han establecido también los porcentajes de cada uno de los sexos.

- La prevalencia deportiva determina un gradiente con los deportes que son practicados por mujeres en los manuales. Dicha prevalencia se establece a partir de imágenes y de presencia. Es una variable que solo se ha estudiado en las deportistas y nos indica qué tipo de deportes -y, por tanto, modelos deportivos- se ofrecen a las alumnas en los manuales.

Para el tratamiento estadístico se ha utilizado el programa Excel, donde se han vaciado los datos recopilados. Se ha incluido también en los resultados el listado de nombres de deportistas mujeres y varones que aparecen en los manuales.

En relación oon la muestra del estudio, esta se compone de dos libros de texto de dos editoriales distintas (tabla 1), cuya elección se hizo, siguiendo a Martínez Bello (2013), atendiendo criterios como:

- La etapa y ciclo. Se eligieron los cursos de $3^{\circ}$ y $4^{\circ}$ de Secundaria por ser la última etapa de educación obligatoria y por su trascendencia de cara a la educación postobligatoria. Según la literatura, la presencia femenina disminuye según se aumenta de nivel educativo (Subirats, 1993; López-Navajas, 2014), por lo que parece pertinente establecer si esto sigue siendo así.

- El idioma de publicación. Se eligió castellano porque cubre un ámbito estatal.

- La existencia de manuales de EF. Para esto, se contactó con las propias editoriales y, como recomiendan Pellejero y Torres (2011), con centros educativos.

- Su elaboración a partir de la LOE, por ser la ley en vigor en el momento de realizar el trabajo de campo.

Una vez elegida y recopilada la muestra, se determinaron las categorías de análisis -ya mencionadas-y se elaboraron las tablas para ordenar los datos.

\section{Resultados y Discusión}

Veamos, a continuación, los resultados de nuestro estudio ordenados por categorías de análisis.

\section{Presenciayrecurrencia}

Los datos reflejados en la tabla 2 muestran la presencia (p) y la recurrencia(r) de las mujeres y los hombres deportistas en los libros de texto analizados. Lo primero que destaca es la absoluta ausencia de mujeres deportistas en la editorial Serbal, obviando las innegables aportaciones de las mujeres a la cultura y al deporte, aunque también debemos indicar que tiene muy pocos nombres de varones. Otro de los aspectos observados en ambas editoriales es que no existe prácticamente recurrencia, es decir, los personajes (tanto hombres como mujeres) suelen aparecer una sola vez. El porcentaje de presencia de Teide es de un $15 \%$ y su recurrencia es de un $17,6 \%$. Estos datos rompen un patrón mayoritario puesto de manifiesto en el estudio de López-Navajas (2014) por el cual el porcentaje de recurrencia femenina siempre es menor que
Tabla 1.

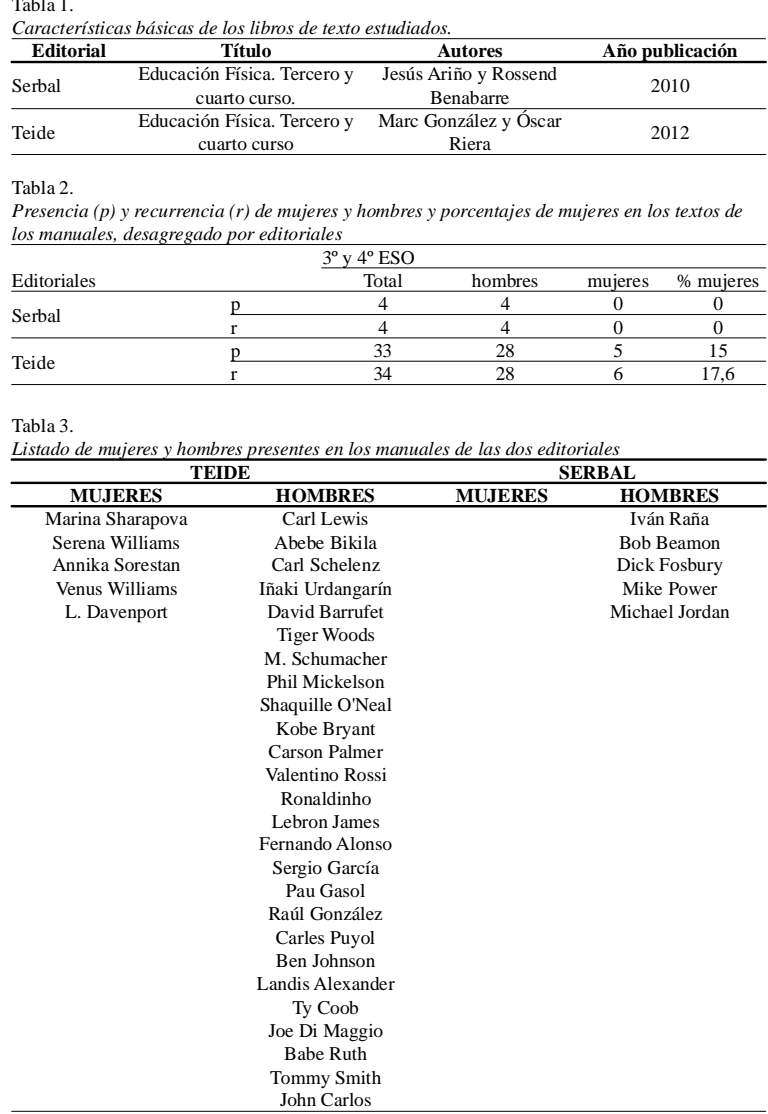

el de la presencia, algo que no sucede con los datos de Teide. Esta falta de presencia y recurrencia de mujeres muestra, entre otras cosas, una muy baja presencia femenina. Además, también se ha observado un tratamiento inadecuado del lenguaje, lo que lleva a la invisibilización de las mujeres (González, 2005). Como señala Díaz Hormigos, (2009: 98) «en la estructura y configuración de determinados usos lingüísticos se hallan indicios de la estructura patriarcal dominante y de la visión androcéntrica». Con estas prácticas, al alumnado se le transmite una visión muy limitada de la presencia femenina, fomentando que se formen identidades y patrones sociales donde se les da un papel secundario a las mujeres, y privando al alumnado del conocimiento adecuado de la práctica deportiva. La tabla 3 con el listado de los deportistas separados por sexos y editoriales nos muestra el diferente tratamiento de unos y otras como referentes deportivos. Ellos son más y ofrecen más modelos deportivos de referencia.

\section{Tratamiento diferenciado por sexos}

Especialmente importante nos parece el tratamiento específico por sexos, pues es el que nos indica la consideración o no del dimorfismo sexual en los humanos y, por ello, resulta un indicador de calidad de contenidos, dado que proporcionaría referencias a chicas y chicos de forma diferenciada. El análisis del bloque de contenidos Condición Física lo vemos reflejado por temas en la Tabla 4. Para ello se han analizado 20 ítems.

El resultado indica que no se tiene presente el dimorfismo sexual. No existeni un solo ítem en las dos editoriales que tenga un tratamiento diferenciado. Esto nos parece especialmente importante por sus implicaciones educativas, mostrándonos que el referente es único y es masculino. La fuerza, la velocidad, la agilidad o la flexibilidad son tratadas en relación a un único referente y este, como decimos, es el masculino. Este dato supone una novedad en los análisis de contenido desarrollados hasta la fecha y se alinea con la intención de este tipo de análisis de desvelar lo no aparente (Piñuel, 2002). Dada su novedad no hemos encontrado en la bibliografía consultada resultados afines con los que compararlo. Por ello, hacemos un alegato, en este punto, para tener en cuenta esta categoría en estudios similares que se lleven a cabo en el 


\begin{tabular}{|c|c|c|c|}
\hline ITEMS & FD SERBAL & FD TEIDE & TRATAMIENTO POR SEXO \\
\hline Aparato locomotor & 1 & 1 & no \\
\hline Aparato digestivo & 1 & & no \\
\hline Aparato cardiovascular & 1 & & no \\
\hline Aparato nervioso & 1 & & no \\
\hline Alimentación & 2 & & no \\
\hline Edad & 2 & & no \\
\hline Consumo drogas & 2 & & no \\
\hline Alcohol & 2 & 1 & no \\
\hline Tabaco & 2 & 1 & no \\
\hline Higiene corporal & 3 & 4 & no \\
\hline Hábitos & 3 & 6 & no \\
\hline Posturas corporales & 3 & 5 & no \\
\hline Resistencia & 4 & 7 & no \\
\hline Fuerza & 5 & 8 & no \\
\hline Velocidad & 6 & 1 & no \\
\hline Flexibilidad & 7 & 2 & no \\
\hline $\begin{array}{l}\text { Capacidades } \\
\text { coordinativas }\end{array}$ & 7 & & no \\
\hline Agilidad & 7 & & no \\
\hline Posturas corporales & & & no \\
\hline Musculatura & & & no \\
\hline
\end{tabular}

Tabla 5.

Prevalencia deportiva de las mujeres deportistas en las dos editoriale

\begin{tabular}{lccc}
\multicolumn{1}{c}{ DEPORTES } & Mujeres SERBAL & Mujeres TEIDE & $\mathbf{N}^{0}$ MUJERES \\
\hline Atletismo & 11 & 5 & 16 \\
Voleibol & 11 & 3 & 14 \\
Baloncesto & 10 & 2 & 12 \\
Danza & 8 & 3 & 11 \\
Estiramientos & 6 & 5 & 11 \\
Balonmano & 8 & 1 & 9 \\
Tenis & & 3 & 7 \\
Fútbol & 4 & 2 & 6 \\
Gimnnasia Rítmica & 2 & 4 & 6 \\
Bádminton & 6 & 1 & 6 \\
Carrera orientación & 4 & 4 & 5 \\
Rugby & & 2 & 4 \\
Natación & 2 & 2 & 2 \\
Snow & & & 2 \\
Deporte Adaptado & & & 1 \\
Escalada & 1 & & 1 \\
Lanzamiento jabalina & 1 & & 1 \\
Lanzamiento disco & 1 & 1 & 1 \\
Lanzamiento peso & 1 & & 1 \\
Golf & & & \\
Ciclismo & & & \\
Escalada & & &
\end{tabular}

futuro. Aun así, los resultados obtenidos en esta categoría de análisis se alinean con los recogidos en el resto del estudio y refuerzan con claridad la tesis de la falta de consideración de las mujeres como referente deportivo.

\section{Prevalencia}

Según comprobamos en la tabla 5, los datos de prevalencia señalan al atletismo como la disciplina en la que aparecen más mujeres. En segundo lugar aparecen deportes de equipo como el baloncesto y voleibol y en tercero la danza, siendo éste el deporte femenino por antonomasia. Cabría resaltar la posición del fútbol, el cual aparece con el mismo número de mujeres que la gimnasia rítmica, una actividad tradicionalmente ubicada en un ámbito feminizado. En las disciplinas que le siguen, como la natación, los lanzamientos, el golf o el ciclismo, se dan una o dos apariciones. En definitiva, hay pocos modelos y pocas representaciones de la mujer.

Los datos de la prevalencia de deportes relacionados con mujeres ponen encima de la mesa un cierto sesgo discriminatorio hacia las mujeres, porque asocian al hombre al modelo dominante deportivo (Táboas \& Rey, 2011). Así, mientras la aparición de los hombres se da más en actividades competitivas como fútbol sala o balonmano, las mujeres tienen menor presencia y menor variedad de modelos. Estos datos coinciden con todas las investigaciones consultadas ubicadas en la misma etapa que esta. Mientras en los trabajos de Táboas, \& Rey (2011) se muestra cómo las mujeres ‘hacen’ más fitness, yoga o taichí y los hombres se dedican al deporte, Parra (2002) observa cómo las mujeres practican aerobic, gimnasia rítmica o bádminton y los hombres se afanan en jugar a fútbol o baloncesto. Dichos resultados se confirman incluso en los libros de texto de Primaria donde la presencia de hombres y mujeres depende del tipo de actividad que contemplemos (Moya et al., 2013), aunque estos datos son menos contundentes que los ofrecidos por las investigaciones ubicadas en Secundaria y Bachillerato. Además, parafraseando a Blández, Fernández y Sierra (2007), estos datos concuerdan con otros que trascienden la investigación sobre los materia- les curriculares y que en el ámbito de la actividad física vinculan al hombre con 'rasgos instrumentales' (asociados a roles activos) y a la mujer con 'rasgos afectivos-expresivos' (asociados con roles pasivos físicamente). Teniendo en cuenta el carácter múltiple de este fenómeno, no sorprende que los chicos muestren una mayor competencia en actividades como el fútbol, mientras que las chicas lo hacen en actividades expresivas, como pueda ser el acrosport (Sevil, Abós, Julián, Murillo, \& García-González, 2015). Parece como si en este proceso donde la pescadilla se muerde la cola, los libros de texto juegan un papel fundamental en la perpetuación del status quo androcéntrico.

\section{Imágenes}

Por último, en la tabla 6 encontramos los datos relativos a las imágenes desagregados por editoriales. Tenemos los datos de todas ellas separados por hombres, mujeres y ambos y a continuación los datos totales de hombres $\left(\mathbf{H}_{\mathrm{i}}\right)$ y de mujeres $\left(\mathbf{M}_{\mathrm{i}}\right)$, así como el porcentaje de mujeres ( $\mathbf{M}_{\mathbf{i}}$ ). De un total de 551 imágenes analizadas en los dos libros de texto se aprecia que la presencia total de mujeres en las imágenes nos da resultados cercanos a la paridad: un $42 \%$ del total de las imágenes son de mujeres deportistas. Concretamente, es en Serbal donde el porcentaje, con un $46 \%$, es el más alto. Dichos resultados son mejores que los que ofrecen el análisis de la mención de las deportistas en los textos. El hecho de que se haya tomado conciencia de la capacidad de las imágenes a la hora de transmitir no solo conceptos y sentimientos (Táboas \& Rey, 2011), sino también estereotipos, puede haber favorecido la mejora de la presencia de mujeres entre las imágenes de los manuales de EF, un dato que nos resulta positivo e indica la línea que se debe continuar.

Ahondando en el análisis de las imágenes, en las tablas 7 y 8 encontramos las imágenes de mujeres separadas por temas en la edito-

Tabla 6.

Imágenes. Total de imágenes desagregadas por editoriales en tres grupos (hombres, mujeres y ambos). Total de hombres $\left(\boldsymbol{H}_{i}\right)$, mujeres $\left(\boldsymbol{M}_{i}\right)$ y porcentajes de mujeres $\left(\boldsymbol{M}_{i}\right)$ desagregadas por editoriales

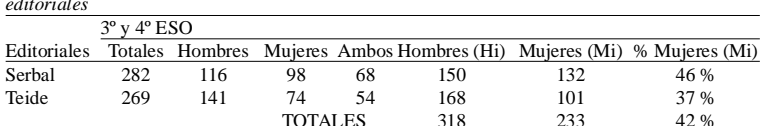

Tabla 7.

Porcentaje de imágenes de mujeres por temas en la editorial Serbal

\begin{tabular}{|c|c|c|c|}
\hline NOMBRE TEMA & MUJERES & HOMBRES & \% MUJERES \\
\hline Las carreras de orientación & 4 & 2 & 62,5 \\
\hline La flexibilidad & 9 & 4 & 60,0 \\
\hline Balonmano & 8 & 3 & 58,6 \\
\hline Atletismo & 12 & 9 & 57,1 \\
\hline Voleibol & 11 & 9 & 54,2 \\
\hline $\begin{array}{l}\text { La higiene deportiva. Primeros } \\
\text { auxilios }\end{array}$ & 6 & 5 & 52,9 \\
\hline La música y la expresión & 10 & 9 & 51,5 \\
\hline La condición física y la salud & 4 & 4 & 50,0 \\
\hline Bádminton & 5 & 5 & 50,0 \\
\hline La resistencia & 4 & 5 & 47,4 \\
\hline Juegos y deportes alternativos & 3 & 6 & 45,2 \\
\hline 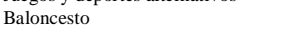 & 10 & 14 & 45,0 \\
\hline La fuerza & 3 & 7 & 37,5 \\
\hline La velocidad & 4 & 8 & 37,5 \\
\hline El cuerpo humano y ejercicio físico & 2 & 5 & 28,6 \\
\hline Fútbol sala & 1 & 10 & 26,3 \\
\hline $\begin{array}{l}\text { El piragüismo y las actividades en la } \\
\text { nieve }\end{array}$ & 2 & 11 & 26,3 \\
\hline TOTAL & 98 & 116 & 47,4 \\
\hline
\end{tabular}

TOTA 98 47,4

Tabla 8.

Porcentaje de imágenes de mujeres por temas en la editorial Teide

El calentamiento

Los deportes de raqueta: el bádminton

La flexibilidad

La expresión corpora

Aparato locomo
La resistencia

Nuevas tendencias de la actividad física

El cuerpo humano y la salud

Voleibol

Deporte adaptado

Historia de la actividad física

Rugby

Rugby
Las capacidades coordinativas

Atletismo

La fuerza

La velocidad

Actividades en el medio natura

Béisbol

Baloncesto

Fútbol sal

TOTAL

\begin{tabular}{ccc} 
MUJERES & HOMBRES & \% MUJERES \\
\hline 6 & 4 & 60,0 \\
4 & 2 & 60,0 \\
7 & 4 & 57,9 \\
6 & 2 & 55,9 \\
3 & 3 & 50,0 \\
5 & 5 & 50,0 \\
5 & 5 & 50,0 \\
4 & 5 & 47,1 \\
4 & 5 & 45,5 \\
2 & 5 & 40,0 \\
6 & 9 & 40,0 \\
4 & 7 & 38,5 \\
4 & 10 & 36,4 \\
4 & 8 & 35,7 \\
3 & 8 & 33,3 \\
2 & 8 & 28,6 \\
3 & 11 & 25,0 \\
2 & 10 & 25,0 \\
0 & 12 & 12,5 \\
0 & 8 & 10,0 \\
0 & 10 & 8,3 \\
74 & 141 & 39,6 \\
\hline
\end{tabular}


rial Serbal y Teide, respectivamente. En ellas comprobamos que los temas de los libros donde menos presencia femenina existe son el fútbol sala y el piragüismo, en el caso del libro de la editorial Serbal, y el fútbol sala y el baloncesto en la editorial Teide, con porcentajes en todos los casos alejados de los que reportan los temas con más presencia femenina.

De nuevo, se observa como la presencia de imágenes de mujeres es mayor en actividades manifiestamente relacionadas con lo femenino (la flexibilidad o la expresión corporal) y siempre con más presencia en deportes como el voleibol que, por ejemplo, el fútbol (el fútbol sala, en este caso). Aunque en el cómputo global, como decimos, el porcentaje de imágenes de mujeres no es muy inferior al de los hombres, los datos no son tan esperanzadores si los analizamos, por ejemplo, desglosados por editorial o por temas. En estos casos, se pone de manifiesto el papel que juega el currículum oculto en la perpetuación de deportes asignados a géneros distintos o la identificación de la mujer con determinadas actividades físicas. Entre otras cosas, esto podría explicar el menor nivel de actividad física realizado por las adolescentes en comparación con los chicos de la misma edad (Beltrán, Sierra, Jiménez, González-Cutre, Martínez, \& Cervelló, 2017). Además, este fenómeno camina en dirección contraria a las normas educativas que, expresamente, ponen encima de la mesa la necesidad de eliminar la discriminación. Éstas no son nuevas y ya la LOGSE (1990) en su artículo 57.3 abogaba por elaborar materiales curriculares sin estereotipos. En su caso, la LOE (2006) expresaba como los libros de texto «deberán reflejar y fomentar el respeto a los principios, valores, libertades, derechos y deberes constitucionales» (disposición adicional cuarta). También la LOMCE se expresa en este sentido.

En este punto, cabría decir que algunos datos nos hacen guardar ciertas esperanzas, como les pasa a Pellejero y Torres (2011), como el caso ya detallado de la casi paridad en la presencia de mujeres y hombres en las imágenes de los libros de texto. Así, la literatura revisada también se hace eco de algunos avances, por ejemplo: a) Táboas y Rey (2011) se refieren a un libro de texto donde se han publicado menos imágenes de deportes y más de actividades no competitivas, cuando éstas últimas se asocian más con las mujeres, b) alguna editorial puntualmente coloca más imágenes de mujeres que de hombres (Moya et al., 2013), o c) en los libros de la etapa de Infantil existe un equilibrio entre las imágenes de hombres y mujeres (Martínez Bello, 2013).

En líneas generales, los datos recogidos de las tres editoriales muestran una realidad donde los estereotipos de género continúan estando presentes y se da una escasa presencia de mujeres practicando deporte. Estos resultados vienen a confirmar los hallazgos de otros trabajos similares desarrollados en el ámbito de la EF (González, 2005; MartínezBello, 2013; Moya et al., 2013, 2014; Táboas \& Rey, 2007, 2011) y de la educación en general (López-Navajas, 2014; Parra, 2002) y que han puesto de manifiesto, en mayor o menor medida un tratamiento desigual en cuestiones de género.

\section{Limitaciones y propuestas}

Las limitaciones de este estudio se relacionan con la muestra estudiada, que implica únicamente los libros de texto de dos editoriales, aunque este hecho concuerda, por ejemplo, con las muestra del estudio de Táboas y Rey $(2007,2011)$. Por ello, pensamos que nuestros datos son pertinentes y vienen a completar las investigaciones desarrolladas anteriormente al respecto y que hemos usado en la discusión de nuestros resultados. En este sentido, cabe pensar que a partir de ahora se precisan nuevas investigaciones, en este caso colaborativas, que propongan usos concretos de los libros de texto desde una perspectiva crítica y que impliquen al profesorado en cuestión.

Desde el punto de vista de las propuestas, los resultados obtenidos tienen una implicación práctica clara: hacer un llamamiento a las editoriales para así, de una vez por todas, contribuir con sus libros de texto a eliminar los estereotipos de género y las discriminaciones que sutilmente se fomentan. Las investigaciones publicadas al respecto, de la que este trabajo forma parte, han puesto sobradamente de manifiesto este hecho, por lo que el desconocimiento ya no es excusa para dejar de abordar estos cambios. En este sentido, a las mismas editoriales y a los responsables de las políticas educativas les proponemos:

- En primer lugar el tratamiento diferenciado del dimorfismo sexual (mujeres y hombres) en el bloque relativo a los contenidos de la Condición Física.

- Una mayor diversidad de modelos deportivos femeninos a través de las imágenes.

- La utilización de menos estereotipos.

- La formación del profesorado para que sea consciente de la presencia y progresión de las mujeres en el deporte.

- La realización de material educativo que tenga a las mujeres presentes como protagonistas.

Mientras esto ocurre, los materiales publicados pueden servir para ahondar en estos conocimientos acerca de las discriminaciones en materia de género, pero también de raza, tipo de cuerpo u orientación sexual. Así, a nivel pedagógico, proponemos:

- Que el propio profesorado acoja críticamente el uso de los libros de texto (Hamodi, 2014) y, más allá de darle una utilidad tradicional, pasiva e unidireccional, se apoye en él de forma crítica y diversa. En este sentido, el profesorado, antes de decantarse por una editorial, podría replicar este trabajo (y los demás reseñados) para detectar cuáles de ellas cumplen con las disposiciones legales al respecto. Con ello, atendemos al argumento de Devís et al. (2001) sobre el carácter moral de esta decisión. Así, dado que el profesorado de EF goza de cierta autonomía a la hora de elegir editorial (Molina et al., 2004), en esta decisión se debe incorporar necesariamente el criterio de la existencia o no de sexismo. A la luz de los resultados obtenidos, se debería rechazar un libro de texto por sexista y discriminatorio (Pellejero \& Torres, 2011),

- Mientras los manuales se ponen al día, el profesorado puede proponer al propio alumnado que participe en el análisis de los libros de texto. Así, igual que en otros lugares se ha planteado el análisis del sexismo en la publicidad (Devís et al., 2001) o en revistas para adolescentes (Oliver, 2001), un trabajo crítico resultaría de motivar al alumnado a crear sus propias categorías para el análisis de contenido y proceder a registrar imágenes y textos en relación con el género.

Con todo, además queremos dejar constancia de la necesidad de nuevas investigaciones, dada la escasez encontrada (Táboas \& Rey, 2011). Una propuesta pasa por desarrollar estudios cualitativos que incorporen la opinión, por ejemplo, de los y las alumnas o de las editoriales. En este punto, como ya hemos señalado, se nos revela fundamental la puesta en práctica de investigaciones colaborativas con la participación del propio profesorado de EF. El objetivo pasa por trascender la simple constatación del conocimiento que tenemos acerca de la EF y su relación con las alumnas; en otras palabras, «debemos enfocar la cuestión de manera pragmática, preguntándonos si podemos hacer algo para mejorar, cuál sería la mejora en cuestión y cómo debemos abordar este tema» (Kirk \& Oliver, 2014:21).

\section{Conclusiones}

Este estudio confirma los resultados hallados en otros trabajos similares y ha venido a corroborar que los libros de texto siguen teniendo un tratamiento desigual en cuestiones de género. A pesar que las imágenes tienen una representación más equitativa, lo que constituye un pequeño avance, ni la mención en los textos ni el tratamiento diferenciado por sexos presentan esa equidad. De hecho, estos dos aspectos nos revelan, mejor queninguno, las carencias y la necesidad de adecuación de los contenidos de EF. En este sentido, pensamos que el estudio desvela la existencia de un androcentrismo latente transmitido precisamente a través del currículum oculto y es así cómo se siguen transmitiendo las desigualdades.

A modo de resumen, podemos recordar cómo los datos arrojan una presencia femenina en las imágenes cercana a la equidad (42 \%). No obstante, el resto de variables analizadas nos muestran un panorama muy diferente: si nos referimos a los textos, encontramos datos que van desde el $0 \%$ (Serbal) hasta el $17 \%$ de Teide, cifras muy escasas de 
representación femenina. Los datos de presencia, recurrencia y especificidad sexual, por el contrario, nos muestran más crudamente el estado de los contenidos educativos en relación a la consideración de las mujeres. Así, resalta sobremanera la nula presencia del tratamiento diferenciado por sexos. Ningún tema en ninguna editorial contiene ese tratamiento. Este es el elemento que con más claridad indica las carencias de los manuales de EF. Y, a su vez, también indica el camino que debemos seguir para mejorar la calidad de los contenidos. Esta falta de tratamiento diferencial y, por tanto, sexista es indicador de ausencia de rigor didáctico: se obvia a la mitad de la población a la que se imparte docencia. Por último, la prevalencia indica que se sigue manteniendo al hombre como modelo dominante deportivo, relacionando a las mujeres con menos actividades y menos variedades. Es por ello que se sigue privando a mujeres y hombres de modelos deportivos centrados en deportes tradicionalmente relacionados con el otro sexo. Ello es indicador de la pervivencia de estereotipos y deja a las alumnas con carencia de modelos de referencia deportiva.

\section{Referencias}

Ariño, J., \& Benabarre, R. (2010). Educación Física. Tercero y cuarto curso. Barcelona: Editorial Serbal.

Beltrán, V.J.; Sierra,A.; Jiménez,A.; González-Cutre, D.; Martínez C., \& Cervelló,E.(2017) Diferencias según género en el tiempo empleado por adolescentes en actividad sedentaria y actividad física en diferentes segmentos horarios del día. Retos, 31, 37.

Blanco, N. (2000). El sexismo en los materiales educativos de la ESO. Sevilla: Instituto andaluz de la Mujer.

Blández, J.; Fernández, E., \& Sierra, M.A. (2007). Estereotipos de género actividad física y escuela: La perspectiva del alumnado. Revista de currículum y formación de profesorado, 11(2). Recuperado de http://www.ugr.es/local/recfpro/ rev112ART5.pdf.

Chevallard, Y., \& Joshua, MA. (1982). Un exemple d'analyse de la transposition didactique: La notion de distance. Recherche en Didactique des Mathématiques, 3(1), 159239.

Delgado, M.A.; Barrera, J., \& Medina, J.(1992). Análisis del libro de texto en la enseñanza de la educación física. Habilidad Motriz, 1, 11-18.

Devís, J. (1998). La salud en la educación física escolar: materiales curriculares para el alumnado de enseñanza primaria. En M. Villamón (dir.), La educación física en el curriculum de primaria (pp. 367-388). Valencia: Generalitat Valenciana.

Devís, J.; Peiró, C.; Molina, J.; Villamón, M.; Antolín, L., \& Roda, F. (2001). Los materiales curriculares en Educación Física: clasificación, uso e investigación. Movimiento, 7, 119- 136.

Devís, J.; Fuentes, J.M., \& Sparkes, A.C. (2005). ¿Qué permanece oculto del currículum oculto? Las identidades de género y de sexualidad en la educación física. Reviste Iberoamericana de Educación, 39, 73-90.

Díaz, M.T. (2009). Androcentrismo social, discriminación lingüística y propuestas para un uso igualitario de la lengua. En C. Fuentes \& E. Alcaide (eds.), Manifestaciones textuales de la descortesía y agresividad y verbal en diversos ámbitos comunicativos (pp. 98-117). Sevilla: Universidad Internacional de Andalucía.

Duran, C.; Lavega, P.; Salas, C.; Tamarit, M., \& Invernó, J. (2015). Educación física emocional en adolescentes. Identificación de variables predictivas de la vivencia emocional. Cultura, Ciencia y Deporte, 10(28), 5-18.

Fernández, J.C. (1996). Los materiales didácticos en educación física. Pixel Bit. Revista de Medios y Educación, 6. Recuperado de http://www.sav.us.es/pixelbit/ artículosn ${ }^{\circ}$ /n6art/art66.htm>

Fernández, E. (2002). Temas transversales: diferencias de género e igualdad de oportunidades en Educación Física. En F. Sánchez Bañuelos (ed.), Didáctica de la Educación Física para Primaria (pp. 181-197). Madrid: Pearson.

Freire, P. (1990). La naturaleza política de la educación. Cultura, poder y liberación. Barcelona: Centro de publicaciones del MEC y Paidós.

Garreta, N., \& Gareaga, P. (1987). Modelos masculino y femenino en los textos de EGB. Madrid: Ministerio de Cultura. Instituto de la Mujer.

Gómez, M.A.; Ortega, E., \& Sainz, P. (2008). Diferencias en la ejecución técnicas en el fútbol: análisis por género y nivel de experiencia en educación física. Retos, 14, 6365.

González, M., \& González, C. (1996). El material de educación física en el marco de la reforma educativa. Apunts. Educacón física y Deportes, 46, 36-41.

González, M. (2005). ¿Tienen sexo los contenidos de la Educación Física escolar? Transmisión de estereotipos de sexo a través de los libros de texto en la etapa de Secundaria. Revista Internacional de Medicina y Ciencias de la Actividad Física y el Deporte, 5, 77-88.

González, M., \& Riera, O. (2012). Educación Física. Tercero y cuarto. Barcelona: Editorial Teide.

González-Palomares, A., \& Rey-Cao, A. (2015). Los contenidos curriculares en las fotografías de los libros de texto de educación física en Secundaria. Retos, 27, 81-85.

Grandes, A. (1999). Atlas de Geografía humana. Barcelona: Tusquets Editores.

Hamodi, C. (2014). ¿Transmiten los libros de texto el valor de la igualdad desde la perspectiva de género? Estudio del lenguaje icónico de dos editoriales. Reviste d'Innovació i Recerca en Educació. REIRE, 7(1), 30-55.
Instituto de la Mujer (2014). Mujeres y hombres en España. Instituto de la Mujer. Recuperado de http://www.inmujer.gob.es/estadisticas/mujeresHombres/docs/2014/ Mujeresyhombres2013.pdf

Kirk, D., \& Oliver, K. (2014). La misma historia de siempre: reproducción y reciclaje del discurso dominante en la investigación sobre la educación física de las chicas. Apunts. Educación Física y Deportes, 116(2), 7-22. doi: http://dx.doi.org/10.5672/ apunts.2014-0983.es.(2014/2).116.01.

Ley de Ordenación General del Sistema Educativo (1990). En Boletín Oficial del Estado (BOE) $n^{\circ}$. 238, de 4 octubre 1990. Recuperado de https://www.boe.es/buscar/ doc.php?id=BOE-A-1990-24172.

Ley Orgánica de Educación (2006). En Boletín Oficial del Estado (BOE) nº. 106, de 4 mayo 2006. Recuperado de http://www.boe.es/diario_boe/txt.php?id=BOE-A2006-7899.

Ley Orgánica para la mejora de la calidad educativa (2013). En Boletín Oficial del Estado, $n^{\circ}$ 295, de 9 de Diciembre de 2013. Recuperado de http://www.boe.es/buscar/pdf/ 2007/BOE-A-2007-6115-consolidado.pdf.

López-Navajas, A. (2014). Análisis de la ausencia de las mujeres en los manuales de la ESO: una genealogía de conocimiento ocultada. Revista de Educación, 363, 282308. doi: 10.4438/1988-592X-RE-2012-363-188

López Rodríguez, A. (2001). Los materiales curriculares en educación física como colaboradores del proceso de enseñanza y aprendizaje. Tándem. Didáctica de la educación física, 4, 34-44.

Martínez Bello, V. (2013). Representación racial, diversidad corporal y género en las imágenes de los libros de texto españoles de educación infantil. Diálogos sobre educación, 7, 1-17.

Martínez Bonafé, J. (2002). Políticas del libro de texto escolar. Madrid: Morata.

Michel, A. (1987). Fuera moldes. Hacia una superación del sexismo en los libros infantiles y escolares. Barcrelona: Unesco-laSal.

Molina, J., Peiró, C., \& Devís, J. (2004). Un estudio sobre los materiales curriculares impresos en E. Física: implicaciones para la formación del profesorado. Movimento, 10(1), 41- 70.

Moreno, M. (1986). Cómo se enseña a ser niña: el sexismo en la escuela. Barcelona: Icaria.

Moya, I., Ros, C., Bastida, A., \& Menescardi, C. (2013). Estereotipos de sexo y raza en las imágenes de los libros de texto de educación física en primaria. Retos. Nuevas tendencias en educación física, deporte y recreación, 23, 14-18.

Moya, I., Ros, C., \& Menescardi, C. (2014). Los contenidos de educación física a través de las imágenes de los libros de texto de educación primaria. Apunts. Educación Física y Deportes, 118(4), 40-47. doi: http://dx.doi.org/10.5672/apunts.20140983.es.(2014/4).118.04

Muñoz, E., Olivera, J., Pérez, J.I., Sánchez, M., \& Sainz, R. (1988). El libro de texto en la educación física de las enseñanzas medias. En M. Chivite \& et al. Aspectos didácticos de educación física 2 (pp. 37-78). Zaragoza: ICE-Universidad de Zaragoza.

Oliver, K.L. (2001). Images of the Body from Popular Culture: Engaging Adolescent Girls in Critical Inquiry. Sport, Education and Society, 6(2), 143-164. doi: http:/ /dx.doi.org/10.1080/13573320120084245

Parra, J. (2002). El sexismo en los libros de texto de Educación Física en segundo ciclo de ESO y Bachillerato. Lecturas: Educar en Castilla la Mancha. Recuperado de http://www.jccm.es/ educación/educar/num_16/opinion.html>.

Pedraz, M. V. (2010). Educación Física e ideología. Creencias pedagógicas y dominación cultural en las enseñanzas escolares del cuerpo. Retos, 17, 76-85.

Pelegrín, A., León, J.M., Ortega, E., \& Garcés, E. (2012). Programa para el desarrollo de actitudes de igualdad de género en clases de educación física en escolares. Educación $X X, 15(2), 271-292$

Pellejero, L., \& Torres, B. (2011). La educación de la sexualidad: el sexo y el género en los libros de texto de Educación Primaria. Revista de Educación, 354, 399-427.

Peñalver, R. (2001). Análisis del sexismo en los libros de texto de ESO. Murcia: Secretaría Sectorial de la Mujer y de la Juventud de la Región de Murcia.

Piedra, J., Ramírez-Macías, G., \& Latorre, A. (2014). Visibilizando lo imposible: creencias del profesorado de educación física sobre homofobia y masculinidades. Retos, 25 , 60-66.

Piñuel, J.L. (2002). Epistemología, metodología y técnicas del análisis de contenido. Estudios de Sociolingüística, 3(1), 1-42.

Posada, L. (2008). Sobre la violencia de género: algunas reflexiones a propósito de la educación. En R. Cobo (Ed.), Educar en la ciudadanía: perspectivas feministas (pp. 81-106). Madrid: Los libros de la Catarata.

Scraton, S. (1992). Educación física de las niñas: un enfoque feminista. Madrid: Morata.

Sevil, J., Abós, A., Julián, J.A., Murillo, B., \& García-González, L. (2015). Género y motivación situacional en Educación Física: claves para el desarrollo de estrategias de intervención. RICYDE. Revista internacional de ciencias del deporte, 41(11) 281-296. doi: http://dx.doi.org/10.5232/ricyde2015.04106.

Subirats, M. (1993). El sexismo en los libros de texto: análisis y propuesta de un sistema de indicadores. Madrid: Instituto de la Mujer.

Táboas, M. I., \& Rey, A. (2007). El cuerpo en las imágenes de los libros de texto de educación física: análisis de dos editoriales. Kronos, 5(11), 25- 30.

Táboas, M. I., \& Rey, A. (2011). Las imágenes en los libros de texto de Educación Física de la ESO: modelos corporales y actividad física. Revista de Educación, 354, 293322

Vilanova, A., \& Soler, S. (2012). La coeducación en la educación física en el siglo XXI: reflexiones y acciones. Tándem. Didáctica de la Educación Física, 40, 75-83.

Villella, J. (2004). El conocimiento profesional de los docentes de Matemáticas en relación con la selección y uso de libros de texto en la clase de geometría para alumnos de 12-14 años. Tesis Doctoral. Universidad de Huelva, Huelva. 